\title{
Asymptotic relations for the Bernstein-Schnabl operators on the unit interval
}

\section{IOAN RAŞA}

\begin{abstract}
.
Asymptotic relations are established for the Bernstein-Schnabl operators on the unit interval. The general results are applied to special sequences of operators, and some known results are obtained as particular cases.
\end{abstract}

Department OF MATHEMATics

TECHNICAL UNIVERSITY OF CLUJ-NAPOCA

MEMORANDUMUlui 28, 400114 Cluj-NAPOCA, Romania

E-mail address: Ioan.Rasa@math.utcluj.ro

Received: 30.10.2011; In revised form: 02.09.2012; Accepted: 15.10 .2012

Key words and phrases. Bernstein-Schnabl operators, asymptotic relations. 